\title{
Južnoslovenski aspekti u mađarskim filmovima
}

\author{
IMRE SZÍJÁRTÓ \\ Eszterházy Károly Főiskola, Mozgóképkultúra Tanszék, HU-3300 Eger, Eszterházy tér 1. \\ Department of Motion Picture, Institute of Visual Arts, Eszterházy Károly University \\ E-mail: szijarto.imre@uni-eszterhazy.hu
}

(Received: 30 November 2017; accepted: 15 January 2018)

\begin{abstract}
The paper explores Hungarian films that make reference to South Slavic cultures. The author examines the problems of cinematic representation and employs the methodology of imagology. The core question of the paper is how Hungarian films represent Yugoslavian (or ex-Yugoslavian) characters. Márk Bodzsár's Heavenly Shift (Isteni müszak) is set in 1992, events on the minor storyline take place in Sarajevo, while the protagonist of the main storyline is an ethnic Hungarian from Vojvodina who illegally crossed the Serbian-Hungarian border. The story of Ibolya Fekete's Bolse vita begins in 1989: the Russian protagonists of the film would like cross over Western Europe through Yugoslavia, and the film ends with archival footage of the ex-Yugoslavian conflict. The protagonist of Ibolya Fekete's Chico takes part in this conflict on the Croatian side and the film depicts events of the war from this point of view. Attila Till's Kills on Wheels (Tiszta szívvel, 2016) features a character of Serbian origin who is portrayed through devices of black humour.
\end{abstract}

Keywords: Hungarian films, South Slavic cultures, Yugoslavian characters, imagology

\section{Uvod}

Ova studija je deo većeg rada, koji je u pripremi i koji izučava vezu između mađarske filmske umetnosti i filmske umetnosti južnoslovenskih država. Puna verzija ovoga rada, koja analizira filmsku proizvodnju u celosti i raznovrsnu vezu između mađarskog i srpskog, hrvatskog, slovenačkog, bosanskog, makedonskog i bugarskog filma, pokriva i paralele i razlike u istoriji mađarskih filmova i filmova južnoslovenskih država, kao i neke tipove sistema odnosa između filmova i stvaralaca. Ova studija analizira one mađarske filmove, u kojima nailazimo na neke južnoslovenske elemente. Na osnovu primera, ispitujem pitanja reprezentovanja filma, što znači da je opravdano koristiti sistem imagologije (ERöss 2005). Glavno pitanje studije je kako mađarski filmovi prikazuju aktere karakterisane kao južnoslovene i kako se u njima pojavljuje Jugoslavija, odnosno njene države naslednice. Međutim, ne može se baš svugde odrediti nacionalnost aktera ili granice prostora gde se radnja odvija, pošto je regija u mađarskim filmovima, pogotovo pre promene sistema, odnosno pre raspada Jugoslavije, zajednički tretirana.

Kao metodološku napomenu, bitno je napomenuti da u ovoj studiji primenjujem mađarsku perspektivu, to jest studija se fokusira na pojavu južnoslovenskih elemenata u mađarskom filmu. Obrnutu pojavu, to jest pojavu mađarskih elemenata u južnoslovenskoj filmskoj proizvodnji, spominjem samo kao primere, u par 
slučajeva, te tako označavam reciprocitet i raznolikost odnosa. Ovu tačku gledišta koristi jedna moja ranija studija, gde sam izučavao mađarske aspekte slovenačkog filma. Spomenuo sam sledeće filmove: Andrej Mlakar: Halgato (1994) i Mokuš (2008), Marko Naberšnik: Petelinji zajrtk (Petlov doručak, 2008), Branko Djurić Djuro: Traktor, ljubezen in rock n'roll (Traktor, ljubav i rokenrol, 2008) i Mitja Novljan: Norega se metek ogne (Luđaka metak neće, 2005) (SzíJÁRTó 2014). Pravi efekti mogu se videti iz radova srpskih reditelja, koji su vezani za Vojvodinu, od kojih vredi spomenuti Živojina Pavlovića i Aleksandra Petrovića. Vojvodina se pojavljuje i u jednom od najistaknutijih filmova mađarske filmske istorije: film Andraša Kovača Hladni dani (Hideg napok, 1966) obrađuje tragično poglavlje suživota srpske i mađarske zajednice.

Vredi podeliti, odnosno razlikovati dve tačke gledišta, znači to da li iz pravca mađarskog filma posmatramo južnoslovenski film ili iz pravca srpskih, hrvatskih i ostalih filmova posmatramo mađarski film, kako bismo mogli sagledati odsnose sa jedinstvenim konceptom. Eventualnu promenu tačke gledišta svugde ću naznačiti u daljem toku studije.

Stvaraoci, koji su na neki način povezani sa Mađarima iz Jugoslavije ili iz država naslednica, čine poseban most između mađarskog i južnoslovenskog kulturnog kruga. Stvaraoci, koji žive u Vojvodini, Hrvatskoj ili Sloveniji su deo različite kulturne ukorenjenosti - na primer, slovenski gumac, Evgen Car je dobio značajnu nagradu za svoju ulogu u slovenačkom filmu, ali ga pamte i kao mađarskog pisca sa postora Pomurja. U filmu Dušana Makavejeva iz 1967 godine, pod nazivom Ljubavni slučaj ili tragedija službenice P.T.T., ulogu Izabele, koja je po fikciji mađarica, glumi ona Eva Ras, čije se ime u različitim izvorima takođe piše na različite načine i koja igra i u drugim filmovima Makevejeva, a nakon toga i u filmu Karolja Vičeka Vatra se kreće (Bolygótüz, 2002), ali se sa njom susrećemo i u mađarskim filmovima Nebeske armije (Mennyei seregek), Akcenat (Ékezet). Znači, rad Eve Ras pokazuje više sistema veze: svojim ulogama se u isto vreme povezuje sa srpskom, vojvođansko-mađarskom i mađarskom filmskom umetnošću.

Po svemu ovome prekograničnim mađarskim filmom možemo nazivati one filmove, čije se stvaranje povezuje sa nekim od mađarskih zajednica, a njihovi stvaraoci se izjašnjavaju kao prekogranični Mađari. U Vojvodini, na bazi i na osnovu zajedničkog postojanjanja tri elementa - infrastruktura, stručnjaci i jezik mađarski film ima šanse, u Hrvatskoj i u na području Pomurja možemo govoriti o mađarskim stvaraocima, a ne o mađarskom filmu. Znači, za stvaraoce, koji potiču sa prostora iz malih mađarskih zajednica, intenzivno važi da njihove radove određuju veze između dve kulture. Najsvežiji primer je Aron Horvat, rođen u Lendavi, koji je u svoju karijeru započeo u okviru slovenačkog školstva i slovenačke filmske produkcije. U prekograničnim mađarskim filmovima istovremeno radi međunarodni, ali barem dvojezični štab. Koprodukcije daju mogućnost za zajedničku saradnju dotičnih susednih država: kao prva mađarsko-srpska koprodukcija se obično spominje Vatra se kreće. Stvaraoci, koji imaju ulogu kulturnog mosta, priznaju se u obe države. Ovo pokazuje i Bronzana Arena filma Karolja Vičeka pod nazivom Parlog (Parlag, 1974), iz tada još jugoslovenske Pule ili posebna 
nagrada Sabolča Tolnai na Mađarskoj Filmskoj Smotri 2001 godine za film $L i$ cem u zemlju (Arccal a földnek), odnosno njegova nagrada za operatera, na Smotri 2007 godine, za film Peščanik (Fövenyóra), koji je snimljen na osnovu dela Danila Kiša. Jedna od najzanimljivijih produkcija je rad Žolta Baloga pod nazivom Božična magija (Karácsonyi varázslat, 2000). Film obrađuje novele jedne mađarske autorke sa područja Pomurja, Gabriele Bence Utroša; pored mađarskog režisera i glumaca takođe iz matične države, u štabu su mesto dobili i lokalni gumci, kao i saradnici iz Regionalnog Studija Televizije Slovenije na području Lendave. Televizija Slovenije je prikazala Božičnu magiju na mađarskom jeziku sa slovenačkim titlom.

\section{Vrste odnosa}

Iz takozvanih spoljnih odnosa - koji ne proističu iz fikcijskog prostora filma opravdano je istaknuti rad onih glumaca, koji su se kretali između dve ili više nacionalnih filmskih produkcija. Iz ovog ugla gledišta važna je ličnost Džoko Rosiča, koji je značajno životno delo stvarao u tri države. Na tipičan način, filmske produkcije više država smatraju ga svojim glumcem, zato za njegovo ime postoji bugarska, srpska i mađarska verzija. Važno je napomenuti da u mađarskom filmu nije reč samo o gostujućoj igri, reč je o angažmanu inostranog glumca. Džoko Rosič je u ovim filmovima, u više njih, predstavio svoju istočnoevropsku stranu, a pored toga u radnji filmova stvaraoci su u više navrata iskoristili i to što je zanimljivo pričao mađarski, zbog čega se ovaj tip odnosa može ubrajati u unutrašnje nazvanim odnosima, na primer u filmu Gabora Rohonji Konjec ili poslednji ček u čaši (Konyec, az utolsó csekk a pohárban, 2007). Prisutnost bugarskog Ichaka Fincija je drugačije prirode, budući da u njegovim ulogama u mađarskim filmovima ne dolazi do izražaja to što je on bugarin ili stranac: Čontvari (Csontváry, 1980), Zbunjeno srce (Szívzür, 1981). Znači, u ovim poslednjim slučajevima nema govora ni o čemu drugome osim angažovanja inostranog glumca, koji u filmu ne izražava svoju nacionalnu pripadnost.

Od koprodukcija, sa našeg stanovišta, zanimljive su one u kojima se pojavljuju kulturne osobine zemalja učesnica, odnosno u svom pogledu na svet prikazuju neku vrstu dvostranog ili višestranog dodira. Najzanimljiviji od ovih radova je mađarski James Bond, koji se odigrava na hrvatskom primorju: Lav se sprema da skoči (Az oroszlán ugrani készül, 1969 - u režiji Đerđa Revesa). Dva dalja primera su film Janoša Edelenji iz 2008 godine Príma primavera, sa glumom Džoka Rosiča, kao i film Stefan Komandareva pod nazivom Svet je velik i iskupljenje vreba iza ugla (2008) sa bugarskim, nemačkim, slovenačkim i mađarskim učešćem. Prvi film je znači ostvarenje mađarskog reditelja, koji sadrži neke bugarske aspekte, a drugi film se pripisuje jednom bugarskom reditelju i ima mađarske elemente. Nije slučajnost da su oba filma road movie. Ovaj žanr omogućava da karakteri putuju kroz više država, tako da radnja obuhvata jedan ceo region. Što se tiče žanra, na ovom mestu vredi naglasiti da je tipično da su likovi u pričama na 
putu, uglavnom automobilom, a putovanje je za njih obično važnije od cilja. Poenta road movie-a je da se njegov glavni junak i priča ne vezuju za princip cilja. Karakteri ne idu od nekud do negde, kao što je to slučaj i kod ova dvo spomenuta filma. U južnoslovenskim državama možemo pronaći predstavnike ovog žanra, koji su objavili svoje podtipove road movie-a i prikazuju regionalne verzije istog. Slika sveta filma Babica gre na jug (režirao Vinci Vogue Anžlovar, slovenački, 1991), Balkankan (režirao Darko Mitrevski, makedonski, 2005) ili Tajnata kniga (Tajna knjiga - režirao Vlado Cvetanovski, makedonski, 2006), Príma primavera ili Svet je velik... upotpunjava se putovanjem u inostranstvo, pošto je prostor država postao malitesan.

Često je kretanje tamo i nazad, što je povezano sa neuspehom i sa nepotrebnošću putovanja. Pravac kretanja može da bude kružni, znači da se akteri tokom putovanja samo prividno kreću unapred, a zapravo se vraćaju na polaznu tačku. Filmovi se često pozivaju na slike starih žanrova, reflektuju na njih, reinterpretiraju ih. Rezultat je smanjenje važnosti, putovanju aktera nedostaje heroizam, avantura na putovanju nije prava, a u bezciljnosću sloboda izgubi svoju važnost. Znači, prostorna veličina istočnoevropskih filmova je ograničena i iz njih nedostaje prava oslobođenost, koja proizilazi iz road movie-a.

Vraćajući se na spoljne odnose i na koprodukcije: možemo spomenuti Eduarda Zaharieva, koji svojim životnim putem i radom takođe oličava mnogo vrsta veza: svoje studije je završio u Mađarskoj, nakon čega je postao determinantna ličnost bugarskog filma. Njegov poslednji film Zakasneli pun mesec (1997) napravljen je u bugarsko-mađarskoj saradnji. Mogao bi biti predmet dalje studije i to da li u njegovim filmovima postoji neki mađarski uticaj.

Među filmovima koji prikazuju intertextualne veze vodimo računa o onima, koji se sadrže pozivanje na druga dela - ovi pozivi mogu biti objašnjajući, to jest citiran film se može i pojaviti u datom filmu, a mogu biti i takvi, koji spominju samo stilistička srodstva ili srodstva vezano za sliku sveta. Film Gabora Rohonji i Čabe M. Kiša pod nazivom Brazilci (Brazilok, 2017) spada u prethodnu grupu, kritičari su Brazilce povezali sa filmovima Emira Kusturice zbog prikazivanja roma u karnevalskom stilu.

$\mathrm{Na}$ intertextualnim vezama se grade oni filmovi u kojima se južnoslovenske države pojavljuju kao mesto radnje ili kao putni cilj aktera, pošto se navedene kulture u ovim slučajevima stave u uzajamni lom svetla - takvi su gore spomenuti road movie filmovi u čijim radnjama se ostvaruje putovanje. Slična je situacija sa onim mađarskim filmovima, u kojima postoji akter koji se može povezati sa prostorom južnoslovenskih država, jer se ovi filmski karakteri predstavljaju na osnovu svojih nacionalnih karakteristika. U nastavku dajem primere za oba tipa.

Unutrašnjim odnosima nazivamo one, koji pokazuju kontakt i interakciju između stvaralaca i dela. Oni se mogu pojaviti u paralelnim gledištima stvaralaca, u približavanju ili u dodiru jezika forme i u tematskim srodstvu. Daljnje područje međukulturalnih odnosa je pitanje recepcije. $U$ pojam recepcije u najširem smislu reči spadaju najrazličitije pojave gostoprimstva: kritični odjek jednog stvaraoca ili filma, dokumenti u vezi distribucije i podaci koji se iz istih mogu pročitati. 
U sledeća tri poglavlja, upotrebljavajući gore navedeni sistem pojmova ću analizirati ću takve mađarske filmove, koji su na neki način povezani sa nekim od južnoslovenskih država i kultura.

\section{Odnosi: preko granice u Jugoslaviju}

U ovom poglavlju ću pričati o četiri takva filma, u kojima akteri beže u Jugoslaviju, to jest barem planiraju, eventualno pokušavaju bekstvo. Iaoko postoje različiti motivi iza njihovih radnji, ali u filmovima je zajedničko oslikavanje Jugoslavije: prelazak preko mađarsko-jugoslovenske granice u svim slučajevima je povezan sa bekstvom od uslova života u Mađarskoj ili sa željom za boljim životom. U pozadini radnje, koja je tada, za vreme odvijanja radnje filma, nazivana dezerstvom i koja je u to vreme bila strogo kažnjavana radnja, najverovatnije se krije ta slika da Austrijsku granicu strogo čuvaju, što znači da vredi krenuti prema Jugoslaviji, koja je po svih pogledima bila smatrana slobodnijom od Mađarske.

Film Andraša Kovača Gazda ergele (Ménesgazda, 1977) se odigrava na jednom, bliže neodređenom mestu, na jednoj poljoprivrednoj ekonomiji, početkom 50-ih godina. O blizini granice svedoči često pojavljivanje graničara, koji drže pod kontrolom tamo smeštene vojnike Hortijeve vojske. Farma je znači, istovremeno farma konja i logor za kažnjavanje iz kojeg akteri filma ne izlaze - okolinu farme film opisuje kao zatvorenu sredinu. Oficiri i podoficiri, koji prikazuju stručnost, drugarstvo i gospodsku Mađarsku iz doba Hortija suprostavljaju se vođi logora, seljačkog porekla, koji se za svoje uzdizanje može da zahvaliti sistemu, koji je nastao posle 1947 godine. Vojnicima se mogućnost bekstva pruža onda kada se poremeti red u logoru i kada vođe i naoružani ljudi iz Rakošijevog sistema izgube nadzor nad dešavanjima. Film ne prikazuje da li je bekstvo vojnika u Jugoslaviju bilo uspešno, a i to spada izvan kruga pokazivanja u filmu, na koji način su u Jugoslaviji, 1950 godine, dočekani vojnici, koji su lišeni svih prava, koja su u Mađarskoj imali, ako su možda uspeli da pređu. Znači, da se Jugoslavija u Gazda ergele pojavljuje kao nužna mogućnost.

Film Karolja Maka Gledajući jedno drugog (Egymásra nézve) snimljena 1982 godine. Glavni lik priče, koja se odigrava 1959 godine je novinarka, koja takođe na kraju filma kreće prema južnoj granici. Motivacija novinarke je slična motivaciji vojnika iz filma Gazda ergele: mogućnosti njenih izbora su veoma sužene, jer svoj posao ne može vršiti po svojim principima. Glavni urednik ne pušta da joj se objavi članak u kojem 1956 godinu naziva revolucijom, takođe je imala problema zbog članaka o nasilnom zadrugarstvu; sistem se takođe meša i u njen privatni život. Žena koja je izgubila sve veze, a koja je zbog svoje homoseksualnosti više puta ponižena, kreće znači prema granici i posle ove tačke Gledajući jedno drugog pokazuje begstvo u potpuno drugom svetlu nego u Gazda ergele: sve u svemu, može se shvatiti samoubistvom kako žena kreće bez ikakvog plana i priprema prema granici i stane pred oružjem graničara. Povreda granice je i ovde rezultat prinudne odluke, a Jugoslavija, koja se pojavljuje samo kao oznaka, kao da bi i u ovom 
filmu značila mogućnost bekstva od mađarskih uslova, ali Gledajući jedno drugog pokazuje i neuspeh bekstva.

U filmu Petera Gotara pod nazivom Vreme staje (Megáll az idő, 1981) takođe se radi o bekstvu, to jest prikazuje se pokušaj bekstva, u šta se akteri upuštaju sredinom 60-ih godina, takođe u južnom pravcu. Iako se Jugoslavija u Vreme staje prikazuje kao od Mađarske slobodnija država, ali kod aktera, koji upravo prelaze iz tinejdžerske dobi, ipak samo u jednoj povezanoj stvari: odatle je lakše stići na zapad. Pred Pierom i Dani Keveš ocrtava se znači nesiguran put Jugoslavija-BečAmerika - bitno je dodati da je otac momka Keveš napustio državu 5. novembra 1956 godine na dan pada revolucije, može se pretpostaviti da je takođe preko Austrije stigao do Amerike. Krajnji ishod bekstva ni ovaj film ne pokazuje, pošto se Pier, koji se sa pokvarenim Wartburgom priprema da udari u rampu, potpuno jednostavno izgubi se iz vizuelnog prostora priče.

Rad Iboje Fekete Bolse vita (1995) se odigrava početkom 90-ih godina u Budimpešti. Stav filma prema istoriji se može opisati na sledeći način: na kraju 80-ih godina i na samom početku 90 -ih istočnoevropske države su preživele neki neviđeni entuzijazam, koji su odredile prvi talasi protesta protiv sistema, osnivanje prvih demokratskih partija, nakon toga ponovo sahranjivanje Imre-a Nađa i njegovih prijatelja, a nakon toga odlazak sovjetskih ekipa. U to doba su države u tranziciji bile izuzetno interersantne za ceo svet, ali je zaiteresovanost brzo splasnula, pošto se, po svedočenju filma, narod brzo razočarao u novo uređeni sistem. Promene film pokazuje kroz više procesa: nadzor nad pijacom, koja je dotad važila za prostor slobode, preuzimaju kriminalci, zatvaraju mesto za izlazak Bolse vita, koje je nekad bila posećena od strane mladih, željnih slobode. Po fikciji filma nadanje, koje je trajalo nekoliko godina, pojavljuje se i u tome što su ruski glumci malo lakše dolazili u Mađarsku, a nakon toga iskorišćavajući putovanje, preko Jugoslavije žele stići na Zapad. Ovo bekstvo ipak ne uspeva i to ne zbog onih razloga, koje smo videli u do sada posmatranim filmovima: junaci u filmova su nespretni, nisu sposobni da se koriste slobodom koja se srušila na njih. Znači, u Bolse vita počinju da važe oni tipičnosti road movie-a o kojima smo već pričali, vidimo poniženi, groteskno putovanje (austrijski graničari vrate nazad dečka koji prodaje noževe, a dva glavna aktera muzičara na duže vreme zastaju u Budimpesti).

Na kraju Bolse vita južnoslovenski ratovi se pojavljuju u snimcima dokumentarnih filmova. Dešavanja u ratu film ugrađuje u taj koncept istorije o kojem je prethodno bilo reči: po shvatanju filma, nakon prelaznog, srećnog perioda, narodi sa ovog prostora će se okrenuti jedan protiv drugog. Film rediteljke pod nazivom Chico (2001) takođe ima južnoslovenske povezanosti: glavni akter učestvuje u južnoslovenskom ratu i film iz ove perspektive prikazuje ratna dešavanja.

\section{Odnosi: archetipizacija u žanrovskim filmovima}

Film Marka Bodžara Božanske smene (Isteni müszak, 2013) se odigrava 1992 godine. Mesto jednog nita radnje je Sarajevo, a drugi nit se može povezati sa jednim glavnim glumcem, koji je vojvođanski mađar i pobegne preko srpske-mađar- 
ske granice. Jedan od karaktera ovog filma, koji koristi elemente horrora, thrillera i crne komedij, vojnik u bekstvu, pokušava da svoju devojku, koja je zarobljena u Sarajevu a koji grad je pod napadom, odvede u Mađarsku, ali priča koja sadrži više obrta, u znaku pokušaju da se road movie preinterpretira, dobija drugačiju obrt: dečka koji radi u hitnoj pomoći u Budimpešti švercuju nazad u Bosnu. Mešovita-žanrovska priroda Božanske smene daje mogućnost da film spoji tradiciju vođenja radnje i formiranja junaka - nekadašnja Jugoslavija i sa njom povezana nekoliko lika se pojavljuju preko grotesknog filtera crnog humora. Srpski karaktera filma Čistim srcem (Tiszta szivvel, 2016 - režirao Atila Til) se takođe stavlja u uslove crnog humora. Mafijaš u Čistim srcem se pojavljuje sa pojedinostima kao u krimi filmovima: nosi crnu jaknu i priča mađarski neprepoznatljivim slavskim akcentom.

\section{Rezime}

U ovoj studiji sam izučavao koje niti povezuju mađarsku filmsku umetnost sa filmovima južnoslovenskih država. Pregledao sam one tipove veza u koje se mogu uvrstiti izabrani mađarski filmovi. Sve elemente sistema veza bi mogli raspakovati u posebna poglavlja, koja bi govorila o tim mađarskim filmovima, koji imaju južnoslovensku povezanost. Preokrenuvši logiku ispitivanja, mogli bismo ispitati mađarske elemente južnoslovenskog filma. Ova studija je u daljem toku ispitivala sliku Jugoslavije u četiri filma, a nakon toga je pregledavala archetipizacijski proces žanrovskih filmova.

\section{Literatura}

ERÖss 2005 = ERÖss Gábor: Az idegen, filmnyelven szólva - Külföldiek és kisebbségek a magyar filmekben (1960-2005). Regio 2005/4: 77-131.

SZIJÁRTÓ 2014 = SZİJÁRTÓ Imre: A Muravidék a szlovén irodalomban és filmben. In: Sokszinü nyelvészet - nyelvi sokszinüség a 21. század elején. Írások Kolláth Anna tiszteletére. Budapest: Tinta, Alsóör: Magyar Média- és Információs Központ Imre Samu Nyelvi Intézet, 2014. 340-346. 